Egyptian Journal of Aquatic Biology \& Fisheries

Zoology Department, Faculty of Science,

Ain Shams University, Cairo, Egypt.

ISSN $1110-6131$

Vol. 25(3): 263 - 279 (2021)

www.ejabf.journals.ekb.eg

\title{
Comparative analysis of 16S rRNA based phylogeny, antibiotic susceptibility, and virulence traits of Arcobacter species recovered from domestic fowl and the Nile tilapia
}

\section{Lamiaa Abdel Ghaffar ${ }^{1}$, Alaa Eldin Eissa ${ }^{2}$, Mahmoud Elhariri ${ }^{1}$,} Mohamed Abdelsalam², Khaled Al-Amry ${ }^{1}$

${ }^{1}$ Department of Microbiology \& Immunology, Faculty of Veterinary Medicine, Cairo University, Giza, 12211, Egypt

${ }^{2}$ Department of Aquatic Animal Medicine and Management, Faculty of Veterinary Medicine, Cairo University, Giza, 12211, Egypt

"Corresponding Author: aeissa2012@cu.edu.eg

\section{ARTICLE INFO}

Article History:

Received: March 25, 2021

Accepted: May 19, 2021

Online: May 30, 2021

Keywords:

Arcobacter species,

Chicken,

Nile tilapia,

PCR,

Virulence genes.

\section{ABSTRACT}

Untreated poultry manure/droppings were used in integrated fish ponds as organic fertilizers. This process could put an additional complexity on the bacterial load within fish's ponds ecosystem. Arcobacter species is one of the most important food-borne zoonotic pathogens that infect humans, animals, fish, and fowl. This study aimed to examine if raw poultry manure could possibly enhance Arcobacter propagation among the cohabitant Nile tilapia. In addition, the comparative phenotypic and molecular characterizations among various Arcobacter spp. retrieved from two diverse animal hosts (the Nile tilapia and fowl) with special reference to antibiotic-resistant and virulence genes traits were also studied. Clinically, the examined Nile tilapias exhibited darkness, fin rot, and skin hemorrhages. Internally, the Nile tilapias displayed severe congestion in internal organs, catarrhal enteritis, and swollen gall bladder. The moribund chickens exhibited mild diarrhea, anorexia, and ruffled feathers. Internally, chickens displayed enlarged spleen and liver, enteritis, and kidney congestion. The bacterial colonies on Arcobacter selective agar appeared small and non-pigmented with an intact edge. The recovered bacterial isolates were identified as Arcobacter spp. depending on the phenotypic characters and PCR. Sequencing of $16 S$ rRNA gene confirmed the identity of Arcobacter butzleri (A. butzleri), A. skirrowii, and A. cryaerophilus in both fish and fowl, while $A$. cloacae was confirmed in fish. PCR confirmed the occurrence of two virulence genes (pldA and $t l y A$ ) in most fish and chicken Arcobacter isolates. All chicken Arcobacter isolates showed resistance against ampicillin, ampicillin-sulbactam, and cefotaxime, and variable susceptibility to ciprofloxacin, aztreonam, imipenem, and amikacin. Fish Aeromonads were sensitive to ciprofloxacin, sulpha-trimethoprim, and amikacin.

\section{INTRODUCTION}

Poultry and aquaculture industries are the largest sectors of animal production in

Egypt (Abu-Elala et al., 2015; Hassan et al., 2019), and several emerging bacterial pathogens are hindering the expansion of these sectors (Augustine \& Shukla, 2015). 
From an economic point of view, untreated chicken manures are usually used in earthen ponds as a source of organic fertilizers to ensure the availability of natural food and as an erratic feeding regime in catfish farms (Prithwiraj et al., 2008). However, using raw chicken manure could increase the microbial load in the fish's rearing ponds, and probably increase public health concerns. Interestingly, several bacterial pathogens were significantly higher in fish ponds getting chicken manure as fertilizers (Omojowo \& Omojasola, 2013).

Arcobacter spp. are gram negative bacteria belonging to Campylobacteraceae family and differentiated from Campylobacter by growing aerobically at both $15^{\circ} \mathrm{C}$ and $30^{\circ} \mathrm{C}$, and microaerophilic condition is needed for their initial isolation (Laishram et al., 2016). Currently, the Arcobacter genus includes 25 species, most of them have been isolated from the feces of livestock and human or from foodstuffs, including chicken, rabbit, poultry, meat, shellfish, fish and water. Arcobacter spp. could infect various animal hosts in addition to human, including fish, domestic chicken, besides lower and higher vertebrates (Atabay et al., 2006; Ramees et al., 2017). Arcobacter cibarius, A. skirrowii, A. butzleri, and A. cryaerophilus are the major etiological agents for foodborne pathogens for human, based on the biochemical, molecular characters, and sequencing of housekeeping genes (Shah et al., 2011; Hassan, 2017; Ramees et al., 2017). Contaminated water and food are the main sources that facilitate the transmission of Arcobacters among different hosts (Rahimi, 2014). Therefore, oral route is the critical step in establishing the infection in human and animal (Scarano et al., 2014). However, both horizontal and vertical transmission of Arcobacter has been documented in animal (Ho et al., 2006). It is difficult to phenotypically differentiate between Campylobacter and Arcobacter due to their similarity in cultural and biochemical characters. Therefore, the combination of phenotypic and molecular assays has shown good results in identifying the Arcobacter (Maugeri et al., 2005). Several molecular detection assays; included PCR, restriction fragment length polymorphism (RFLP), real time PCR and multiplex PCR (m-PCR); were applied for Arcobacter spp. identification and differentiation. PCR method was developed to amplify 16S rRNA for the detection of the genus of Arcobacter (Harmon \& Wesley 1996). Species-specific multiplex PCR assay was developed to amplify variable regions of $16 \mathrm{~S}$ rRNA and $23 \mathrm{~S}$ rRNA for the simultaneous identification of A. skirrowii, A. butzleri and A. cryaerophilus (Houf et al., 2002).

Arcobacter spp. have been linked with different diseases conditions in animals such as diarrhea, severe enteritis, colitis, mastitis and abortion (Collado \& Figueras 2011; Bath et al., 2013). Arcobacter spp. was also incriminated in different diseases condition in human such as intermittent and chronic or watery diarrhea, bacteremia, septicemia, abdominal pain, nausea, and other gastrointestinal manifestations (Fisher $\boldsymbol{e t}$ al. 2014; Van den Abeele et al., 2014). This bacterial species could induce disease condition in some turkey strains but not in conventional chicken (Wesley \& Baetz 1999). 
Interestingly, farmed rainbow trout was naturally infected with A. cryaerophilus and the clinical signs included hemorrhages in intestine and muscles, pale gills, abnormal color, deformity of upper jaw, swollen kidney, damaged spleen and skin ulcers, (Aydin et al., 2000, 2002; Yildiz \& Aydin 2006). Arcobacters harbored ten virulence genes, namely; pldA (phospholipase gene), cadF, cj1349 (fibronectin binding proteins), tlyA (hemolysin gene), ciaB (invasion gene), mviN (peptidoglycan biosynthesis), hecA (adhesion), hecB (lysis of cells), $\operatorname{irg} A$ and $\operatorname{iroE}$ (iron acquisition) (Douidah et al. 2012). Those genes might enable bacteria to adhere and invade the host tissues, spread and lysis the erythrocytes. Therefore, Arcobacters are emerging food-borne pathogens and their clinical importance has increased in human and animal health.

Despite increased pathogenic importance, there is scanty information regarding the incidence, isolation and identification of Arcobacter species in the Nile tilapia and poultry in Egypt. In addition, the comparison of Arcobacter spp. recovered from the Nile tilapia and poultry, in terms of $16 S$ rRNA sequence analysis, antibiotic resistance and occurrence of virulence genes, has not yet been explored. Therefore, this study aimed to investigate the prevalence of various Arcobacter species pathogens in poultry, the Nile tilapia and water samples collected from retail markets and fish ponds in Egypt. The phenotypic characterization of retrieved Arcobacter spp. strains were performed using biochemical and antibiotic resistant methods. In addition, the phylogenetic tree of $16 \mathrm{~S}$ rRNA sequences was constructed to identify and determine the phylogenetic relationships within Arcobacter spp. recovered from both poultry and the moribund Nile tilapia Furthermore, the occurrence of putative virulence genes (i.e., pldA and tlyA genes) has been investigated and their distribution within the poultry and fish was also studied.

\section{MATERIALS AND METHODS}

\section{Samples collection}

All national and institutional guidelines for the use and care of the Nile tilapia and chickens were adopted. Samples of chicken were randomly purchased from different retail markets located at Giza governorate, Egypt. Sampling procedure was performed from both apparently healthy and moribund chickens suffering from enteritis. A total of 100 different samples of chicken pieces were collected including skin, muscles, internal organs, intestinal samples and cloacal swabs (Eissa et al., 2012). On the other hand, a total of 100 cultured Nile tilapia were randomly collected from fish farm located at the vicinity of Burullus Lake. Raw poultry manure was used as organic fertilizers and fish feed (Eissa et al., 2012). Recently, this farm has suffered from disease outbreaks among the farmed tilapia. In addition, a total of 10 water samples were randomly collected using sterile screw capped bottle from different sites in earthen pond at $15 \mathrm{~cm}$ below the water surface. Water samples and swabs were immediately transferred to the Microbiology 
Department and Aquatic Animal Health Department Labs using an insulated icebox for processing and bacteriological examination (Eissa et al., 2015; Jakeen et al., 2020).

\section{Isolation media}

Preparation of Arcobacter enrichment broth was performed using Arcobacter Selective Broth Base (Himedia, M1894, Mumbai, India) with Arcobacter selective supplement (Himedia, FD304, Mumbai, India) containing four antimicrobials (Amphotericin B, Cefoperazone, 5-Fluorouracil, and Novobiocin) according to Ramees et al. (2017). Moreover, the preparation of Arcobacter blood agar was performed by adding defibrinated sheep blood 5\% (v/v) and Arcobacter selective supplement (Himedia, FD304, Mumbai, India) in agar base according to Suelam (2013) and Hassan (2017).

\section{Preparation of chicken samples}

Chicken carcass samples were processed using rinsing method technique. Tissue samples were vigorously shaken in sterile plastic cups containing sterile distilled water for 2 minutes then $1 \mathrm{ml}$ of mixed sample was resuspended into Arcobacter enrichment broth containing Arcobacter specific supplement. On the other hand, sterile swabs were inserted into the cloacal of birds and gently swabbing the mucosal lining of vent. Cloacal swabs were placed into sterile tubes containing sterile distilled water and vortexed for seconds, and then $1 \mathrm{ml}$ of withdrawn fluid was resuspended into Arcobacter specific broth (Suelam, 2013; Hassan, 2017).

\section{Preparation of fish and water samples}

Sterile swabs were used to collect samples from skin mucus and intestines of the investigated Nile tilapia fish and placed into sterile tubes containing sterile distilled water, vortexed shortly, then $1 \mathrm{ml}$ of mixed fluid was resuspended into Arcobacter specific broth. On the other hand, $1 \mathrm{ml}$ from each water sample; collected from fish ponds; was resuspended into $9 \mathrm{ml}$ of Arcobacter specific broth (Ramees et al., 2017). The inoculated Arcobacter enrichment broth tubes were incubated at $30^{\circ} \mathrm{C}$ for $48 \mathrm{~h}$ under microaerophilic conditions in a $\mathrm{CO} 2$ incubator. A loopful from the incubated enrichment broth was spread onto Arcobacter selective agar media and Arcobacter blood agar media, and then incubated at $30{ }^{\circ} \mathrm{C}$ for $48 \mathrm{~h}$ until the appearance of visible colonies.

\section{Phenotypic characterization of Arcobacter spp.}

The suspected colonies of Arcobacter spp. were purified by streaking on Arcobacter specific medium. Purified colonies were then presumptively identified with gram staining and motility tests, followed by a series of conventional biochemical tests including catalase, oxidase, urease, nitrate reduction, salt tolerance, and indoxyl acetate hydrolysis tests. Suspected isolates were preserved in Arcobacter selective broth with $15 \%$ (vol/vol) glycerol (LB; Difco, MD, USA) at $-80^{\circ} \mathrm{C}$ for further confirmation using molecular techniques.

\section{DNA extraction}

All Arcobacter spp. isolates were aerobically grown on Arcobacter selective agar, and then incubated at $30^{\circ} \mathrm{C}$ for $48 \mathrm{~h}$. Briefly, genomic DNA extraction from cultivated 
strains was performed using Qiamp DNA mini kit (Qiagen, Germany) following the conditions described by the manufacturer's instructions. The quality of purified DNA was tested using electrophoresis (Abdelsalam et al., 2015a, 2015b, 2017). The purified genomic DNA was subjected to PCR using the primers listed in Table (1).

Table 1: Primers used in this study.

\begin{tabular}{|c|c|c|c|}
\hline Primer & Sequence & Product & References \\
\hline $\begin{array}{l}\text { Arcobacter genus } 16 \mathrm{~S} \\
\text { rRNA }\end{array}$ & $\begin{array}{l}\text { Arco-I: 5'-AGAGATTAGCCTGTATTGTAT-3' } \\
\text { Arco-II: 5'-TAGCATCCCCGCTTCGAATGA-3' }\end{array}$ & $1.2 \mathrm{~kb}$ & $\begin{array}{l}\text { Harmon and } \\
\text { Wesley (1996) }\end{array}$ \\
\hline A. butzleri $16 \mathrm{~S}$ rRNA & $\begin{array}{l}\text { BUTZ: 5'-CCTGGACTTGACATAGTAAGAATGA-3 } \\
\text { ARCO: 5'-CGTATTCACCGTAGCATAGC-3' }\end{array}$ & $401 \mathrm{bp}$ & Houf et al. (2002) \\
\hline A. skirrowii 16s rRNA & $\begin{array}{l}\text { SKIR: 5'-GGCGATTTACTGGAACACA-3' } \\
\text { ARCO: 5'-CGTATTCACCGTAGCATAGC-3' }\end{array}$ & $641 \mathrm{bp}$ & Houf et al. (2002) \\
\hline $\begin{array}{l}\text { A. cryaerophilus } 23 \mathrm{~S} \\
\text { rRNA }\end{array}$ & $\begin{array}{l}\text { CRY1: 5'-TGCTGGAGCGGATAGAAGTA-3' } \\
\text { CRY2: 5'-AACAACCTACGTCCTTCGAC-3' }\end{array}$ & $257 \mathrm{bp}$ & Houf et al. (2002) \\
\hline pldA & $\begin{array}{l}p l d A-f: \text { 5'-TTGACGAGACAATAAGTGCAGC-3' } \\
p l d A-r: \text { 5'-CGTCTTTATCTTTGCTTTCAGGGA-3' }\end{array}$ & $293 \mathrm{bp}$ & $\begin{array}{l}\text { Douidah et al. } \\
\text { (2012) }\end{array}$ \\
\hline $\operatorname{tly} A$ & $\begin{array}{l}\text { tlyA-f: 5'-CAAAGTCGAAACAAAGCGACTG-3' } \\
\text { tlyA-r: 5'-TCCACCAGTGCTACTTCCTATA-3' }\end{array}$ & $230 \mathrm{bp}$ & $\begin{array}{l}\text { Douidah et al. } \\
\text { (2012) }\end{array}$ \\
\hline
\end{tabular}

\section{PCR amplifications}

The Arcobacter genus specific PCR assay was performed to amplify $1.2 \mathrm{kbp}$ region of $16 \mathrm{~S}$ rRNA gene with the primer pairs (Arco-I and Arco-II) by using the procedure described by Harmon and Wesley (1996). Bacterial isolates that were ascribed to Arcobacter genus identity, were subjected to species-specific PCR. Speciesspecific PCR amplifications with specific primers pairs were performed to assign isolates to A. butzleri, A. skirrowii and A. cryaerophilus by using the procedure described by Houf et al. (2002). The specific primers yield 641 bp fragment of $16 \mathrm{~S}$ rRNA of $A$. skirrowii, $401 \mathrm{bp}$ fragment of 16S rRNA of A. butzleri and $257 \mathrm{bp}$ fragment of 23S rRNA of A. cryaerophilus.

\section{Sequencing of $16 S \mathrm{rRNA}$ gene}

The amplified regions of $16 S$ rRNA gene of seven Arcobacter spp. strains were purified and directly sequenced in two directions using the Arcobacter genus specific primer on ABI 3730 automated sequencer (Applied biosystem ${ }^{\circledR}$, Foster city, CA, USA). 
The obtained sequences were evaluated using BioEdit version 7.0 (Hall, 1999). The assembled nucleotide sequences of Arcobacter spp. isolates were then aligned with other Arcobacter spp. 16S rRNA regions available in GenBank using the BLAST available in (https://blast.ncbi.nlm.nih.gov/Blast.cgi). The phylogenetic tree was then constructed by using the neighbor-joining method of MEGA X (Kumar et al., 2016). The following parameters were used: model Kimura two step algorithm; patterns are homogeneous; substitutions contained transversions and transitions; variation rate were uniform and partial deletion. Although varieties of complicated methods are used for phylogenetic tree-making, this method resolves the relationships of different Arcobacter spp. at branch terminals. Campylobacter fetus and Helicobacter cinaedi were selected as the out-group.

\section{Nucleotide sequence accession numbers}

The partials nucleotide sequence of $16 \mathrm{~S} r R N A$ locus of chicken and fish Arcobacter spp. strains were submitted to the GenBank database.

\section{Putative virulence genes}

All Arcobacter spp. strains were exposed to PCR assays to investigate the occurrence and distribution of two virulence genes: the phospholipase gene (pldA) and the hemolysin gene (tlyA) as described by Douidah et al. (2012). Briefly, $5 \mu \mathrm{L}$ of each DNA was amplified in $25 \mu \mathrm{L}$ of mixture reaction consisting of a $2 \mathrm{X}$ Taq polymerase master mix, 10 pmol of primers. PCR was performed by Conventional PCR (Applied biosystems Veriti $96 \mathrm{TC}$ ) with an initial denaturation step of 5 minutes at $95^{\circ} \mathrm{C} ; 35$ cycles of 15 second at $94^{\circ} \mathrm{C} ; 30$ second at $52^{\circ} \mathrm{C}$ annealing temperature for the pldA and $51^{\circ} \mathrm{C}$ $\boldsymbol{t l y} \boldsymbol{A}$ genes, respectively; and 1 minute at $72^{\circ} \mathrm{C}$ followed by a 5 minutes final extension at $72^{\circ} \mathrm{C}$. To determine the presence of the desired amplicon, electrophoresis was done on $1.5 \%$ gel agarose stained by ethidium bromide, and then the products were visualized by UV transilluminator. The sizes of the PCR product of amplifying the pldA and tlyA genes were $293 \mathrm{bp}$ and $230 \mathrm{bp}$, respectively.

\section{Antimicrobial susceptibility}

Susceptibility of Arcobacter spp. to different antimicrobials was assessed on Muller- Hinton agar (Difco laboratories) by disc diffusion method according to Eissa (2016) using the following antibiotic discs: amoxicillin $(30 \mu \mathrm{g})$, amoxiclav $(30 \mu \mathrm{g})$, ampicillin-sulbactam $(20 \mu \mathrm{g})$, amikacin $(30 \mu \mathrm{g})$, Aztreonam (10 ug), cefotaxime $(30 \mu \mathrm{g})$, Ceftriaxone $(30 \mu \mathrm{g})$, ciprofloxacin $(5 \mu \mathrm{g})$, Ceftazidime $(30 \mu \mathrm{g})$, Cefepime $(30 \mu \mathrm{g})$, gentamicin $(10 \mu \mathrm{g})$, Imipeneme $(10 \mu \mathrm{g})$, Cephalexin $(30 \mu \mathrm{g})$, Doxycycline $(30 \mu \mathrm{g})$ and trimethoprim-sulfamethoxazole $(25 \mu \mathrm{g})$. The inhibition zones were measured according to the Clinical Laboratory Standard Institute Guidelines, CLSI (Weinstein \& Lewis 2020). The investigated Arcobacter spp. isolates were recognized as resistant, susceptible, or intermediate against the tested antimicrobial agents. 


\section{RESULTS}

\section{Clinical examination}

The investigated Nile tilapia, $O$. niloticus showed dark discoloration, fin rot scales detachment, and patches of hemorrhages on the body. The internal organs of the examined Nile tilapia revealed severe congestion in spleen, liver, kidney, brain, gonads and gut, while gall bladder was swollen and distended with bile together with marked gastroenteritis. On the other hand, the diseased chickens showed diarrhea, impaired appetite, depression, and ruffled feathers. Internally, the investigated chickens revealed air saculitis, pericarditis, enlarged spleen and liver with necrotic foci, enteritis, unabsorbed yolk sac and nephrosis.

\section{Isolation and identification of Arcobacter spp.}

Small, pinpoint, non-pigmented, translucent and convex with intact edge colonies of chickens and the Nile tilapia Arcobacter spp. appeared on Arcobacter specific agar medium. Further, these isolates revealed alpha-hemolysis on Arcobacter blood agar. All bacterial isolates $(n=35)$ were identified as Arcobacter spp. depending on the following phenotypic characters. All isolates were gram-negative, motile, slightly curved short bacilli, positive to oxidase, catalase, indoxyl acetate hydrolysis test and nitrate reduction test. All isolates were negative to urease test, and hippurate hydrolysis test.

\section{Incidence of Arcobacter}

The highest percentage of Arcobacter spp. isolation was recorded from chicken cloaca (14 out of 50 cloacal samples), followed by fish intestine ( 9 out of 50 intestinal samples), followed by chicken pieces ( 7 out of 50 chicken pieces), fish mucus (3 out of 50 mucus samples) and finally water samples of fish pond ( 2 out of 10 samples). The incidence of Arcobacter spp. among different chicken and fish samples is shown in Table (2).

Table 2: Prevalence of Arcobacter spp. in different samples.

\begin{tabular}{lccc}
\hline Samples type & $\begin{array}{c}\text { Number of collected } \\
\text { samples }\end{array}$ & $\begin{array}{c}\text { Number of contaminated } \\
\text { samples }\end{array}$ & $\begin{array}{c}\% \text { of contaminated } \\
\text { samples }\end{array}$ \\
\hline Fish mucus & 50 & 3 & $8 \%$ \\
\hline Fish Intestines & 50 & 9 & $18 \%$ \\
\hline Chicken Cloaca & 50 & 14 & $28 \%$ \\
\hline Chicken pieces & 50 & 7 & $18 \%$ \\
\hline Fish pond & 10 & 2 & $30 \%$ \\
\hline
\end{tabular}




\section{PCR identification}

All recovered isolates $(n=35)$ were PCR positive for Arcobacter using the universal Arcobacter genus specific primers. Interestingly, seventeen isolates $(48.5 \%)$ were identified as A. butzleri, nine isolates (25.7\%) were identified as A. skirrowii, and eight isolates $(22.9 \%)$ were identified as A. cryaerophilus using the specific primer of each species (Fig. 1). In contrast, one isolate (2.9\%) was PCR negative for A. butzleri, A. skirrowii, and A. cryaerophilus using the specific primer of each species. The profiles numbers of Arcobacter isolates are shown in (Table 3).

Table 3: Phenotypic and molecular characterization of retrieved Arcobacter species.

\begin{tabular}{|c|c|c|c|c|c|}
\hline $\begin{array}{l}\text { Arcobacter } \\
\text { spp. }\end{array}$ & $\begin{array}{l}\text { Nitrate } \\
\text { reduction/ } \\
\text { Oxidase }\end{array}$ & $\begin{array}{l}\text { Urease/ } \\
\mathrm{H} 2 \mathrm{~S}\end{array}$ & $16 S$ rRNA Accession no. & $\begin{array}{l}\text { positive } \\
\text { isolates }\end{array}$ & $\begin{array}{l}\text { Total } \\
\text { isolates }\end{array}$ \\
\hline A. cloacae & + & - & MW509786 (Nile tilapia) & 1 & 1 \\
\hline \multirow[b]{2}{*}{ A. butzleri } & \multirow[b]{2}{*}{+} & \multirow[b]{2}{*}{-} & MW509787 (Nile tilapia) & $5 *$ & \multirow[b]{2}{*}{17} \\
\hline & & & MW509788 (Chicken) & 12 & \\
\hline \multirow[b]{2}{*}{ A. skirrowii } & \multirow[b]{2}{*}{+} & \multirow[b]{2}{*}{-} & MW509789 (Nile tilapia) & 4 & \multirow[t]{2}{*}{9} \\
\hline & & & MW509790 (Chicken) & 5 & \\
\hline \multirow{2}{*}{$\begin{array}{l}\text { A. } \\
\text { cryaerophilus }\end{array}$} & \multirow[t]{2}{*}{+} & \multirow[t]{2}{*}{ - } & MW509791 (Nile tilapia) & 4 & \multirow[t]{2}{*}{8} \\
\hline & & & MW509792 (Chicken) & 4 & \\
\hline
\end{tabular}

*these isolates numbers of $A$. butzleri included both the Nile tilapia and water pond isolates.

\section{Phylogenetic analysis}

The partial sequences of the $16 S$ rRNA gene of the investigated isolates were obtained. The divergence and comparison of those nucleotide sequences showed that all isolates are deeply embedded in Arcobacter spp. group. The accession numbers of the sequenced 16S rRNA genes of Arcobacter spp. that recovered from the moribund Nile tilapia were MW509786, MW509787, MW509789, and MW509791, while those recovered from chicken were MW509788, MW509790, and MW509792. Accession number (MW509786) showed 99.93\% similarity to $16 \mathrm{~S}$ rRNA of A. cloacae (CP053833.1, MG195892.1, and NR_117570.1). Accession number (MW509787) showed $99.39 \%$ similarity to $16 \mathrm{~S}$ rRNA of A. butzleri (CP041386.1, CP040507.1, and LT906455.1), while the accession number (MW509788) exhibited 99.86\% similarity to 16S rRNA of $A$. butzleri (CP041386.1, CP040507.1, and LT906455.1). The intraspecies similarity for chicken $A$. butzleri and the tilapia A. butzleri isolates was $99.24 \%$ with 10 nucleotide differences. On the other hand, accession number (MW509789) showed 99.78\% similarity to 16S rRNA of A. skirrowii (CP032099.1, and MG195899.1), while 
the accession number (MW509790) showed 99.93\% similarity to $16 \mathrm{~S}$ rRNA of $A$. skirrowii (CP032099.1, and MG195899.1). The intraspecies similarity for chicken $A$. skirrowii and the tilapia A. skirrowii isolates was $99.71 \%$ with 4 nucleotide differences.
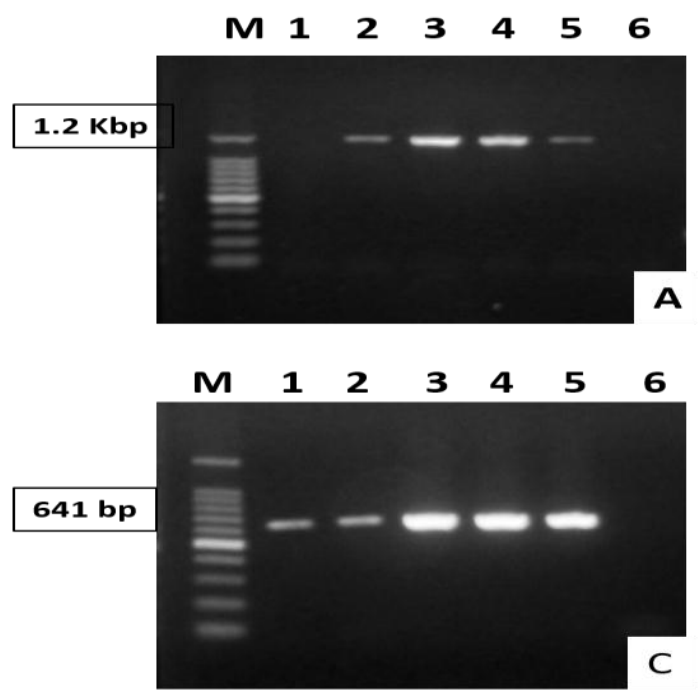
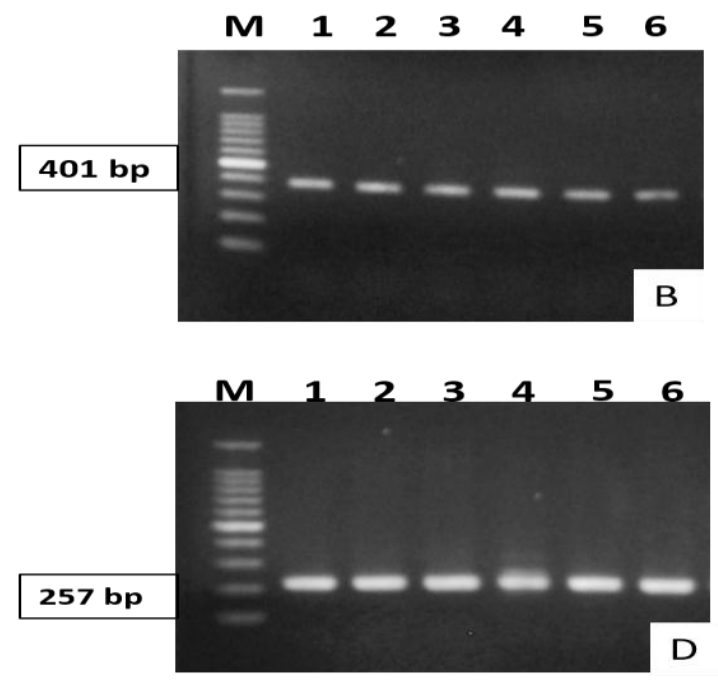

Fig. 1-A: Agarose gel electrophoresis of Arcobacter genus specific PCR amplified 16S rRNA gene using Arco-I and Arco-II primers, 1-B: A. butzleri specific PCR amplified 16S rRNA using BUTZ and ARCO primers, 1-C: A. skirrowii specific PCR amplified 16S rRNA using SKIR and ARCO primers, 1-D: A. cryaerophilus specific PCR amplified 23S rRNA using CRY1 and CRY2

On the other hand, accession number (MW509791) showed 99.86\% similarity to 16S rRNA of A. cryaerophilus (CP021072.1, CP032823.1 and MG195893.1), while the accession number (MW509792) showed 99.64\% similarity to $16 \mathrm{~S}$ rRNA of $A$. cryaerophilus (CP021072.1, CP032823.1 and MG195893.1). The intraspecies similarity for chicken A. cryaerophilus and tilapia A. cryaerophilus isolates was $99.49 \%$ with 7 nucleotide differences. Based on the previous sequences alignment, tilapia Arcobacter spp. isolates were identified as A. butzleri (MW509787), A. skirrowii (MW509789), A. cloacae (MW509786) and A. cryaerophilus (MW509791), while chicken Arcobacter spp. isolates were confirmed to be A. butzleri (MW509788), A. skirrowii (MW509790), and A. cryaerophilus (MW509792).

The constructed neighbor-joining tree method derived on Kimura 2-parameter model showed that strong nodal support was formed of two clades. The first clade composed of three sublades. The first subclade grouped $A$. butzleri isolates in this study with other isolates of $A$. butzleri to form one branch. The second subclade grouped $A$. cryaerophilus isolates of this study together with other $A$. cryaerophilus isolates with a bootstrap value of $98 \%$. The third subclade included A. skirrowii isolates that grouped 
with other A. skirrowii with a high bootstrap value of $100 \%$. The second clade included A. cloacae in this study grouped with other A. cloacae to form a monophyletic group (Fig 2).

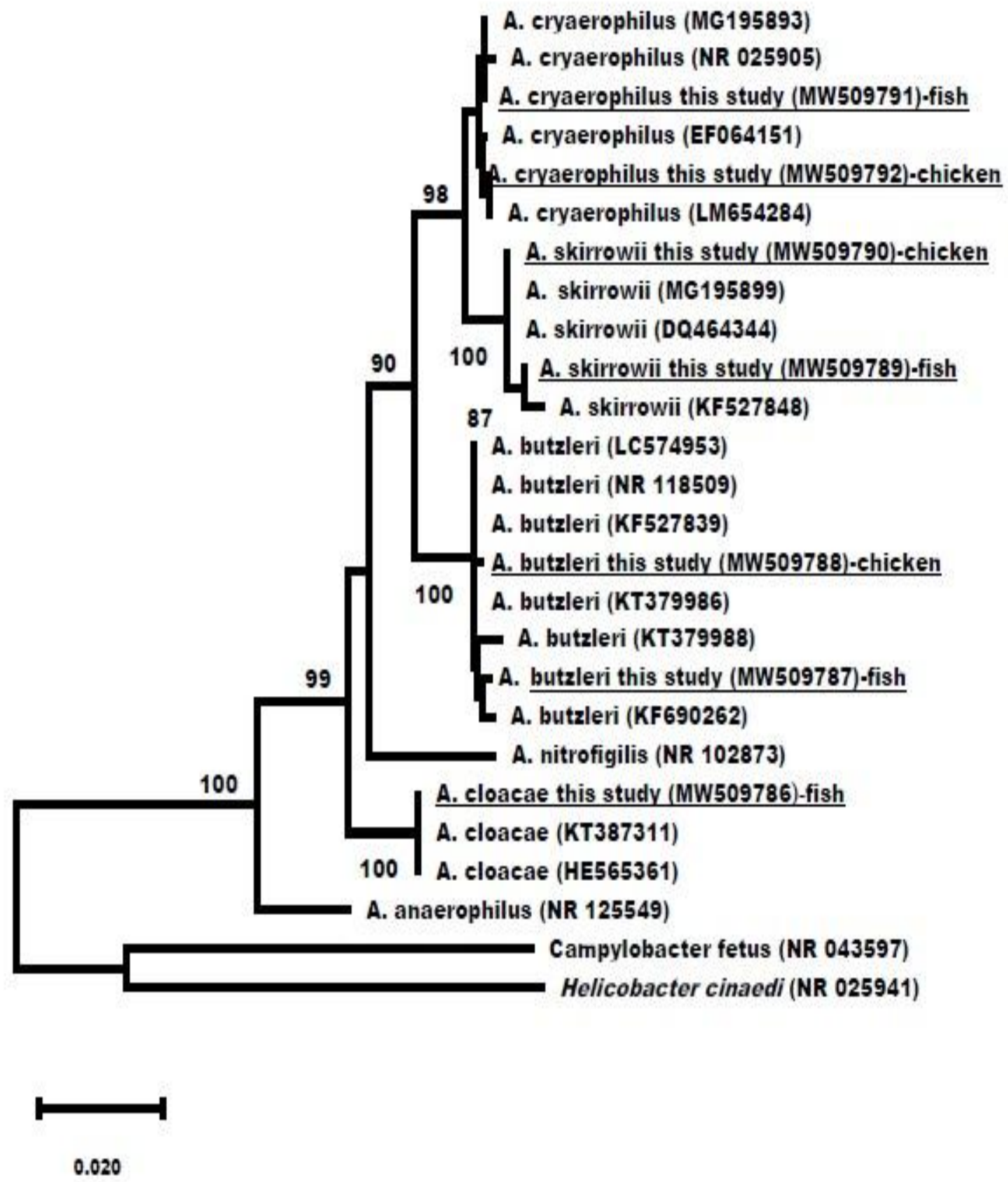

Fig. 2: Phylogenetic tree constructed based on the comparative sequences' analysis of the $16 \mathrm{~S}$ rRNA gene obtained in this study, showing the intra-and interspecies 
relationship among the chicken and the Nile tilapia strains of Arcobacter spp. in this study and other related isolates of Arcobacter spp.

\section{Arcobacter virulence genes}

In this study, two virulence genes ( $p l d A$ and tlyA) were screened in Arcobacter spp. isolates through PCR. The pldA and tlyA virulence genes were detected in 12 and 10 out of 14 isolates of fish Arcobacter spp., respectively. On the other hand, pldA and tlyA virulence genes were detected in 20 and 17 out of 21 isolates of chicken Arcobacter spp., respectively (Fig. 3).
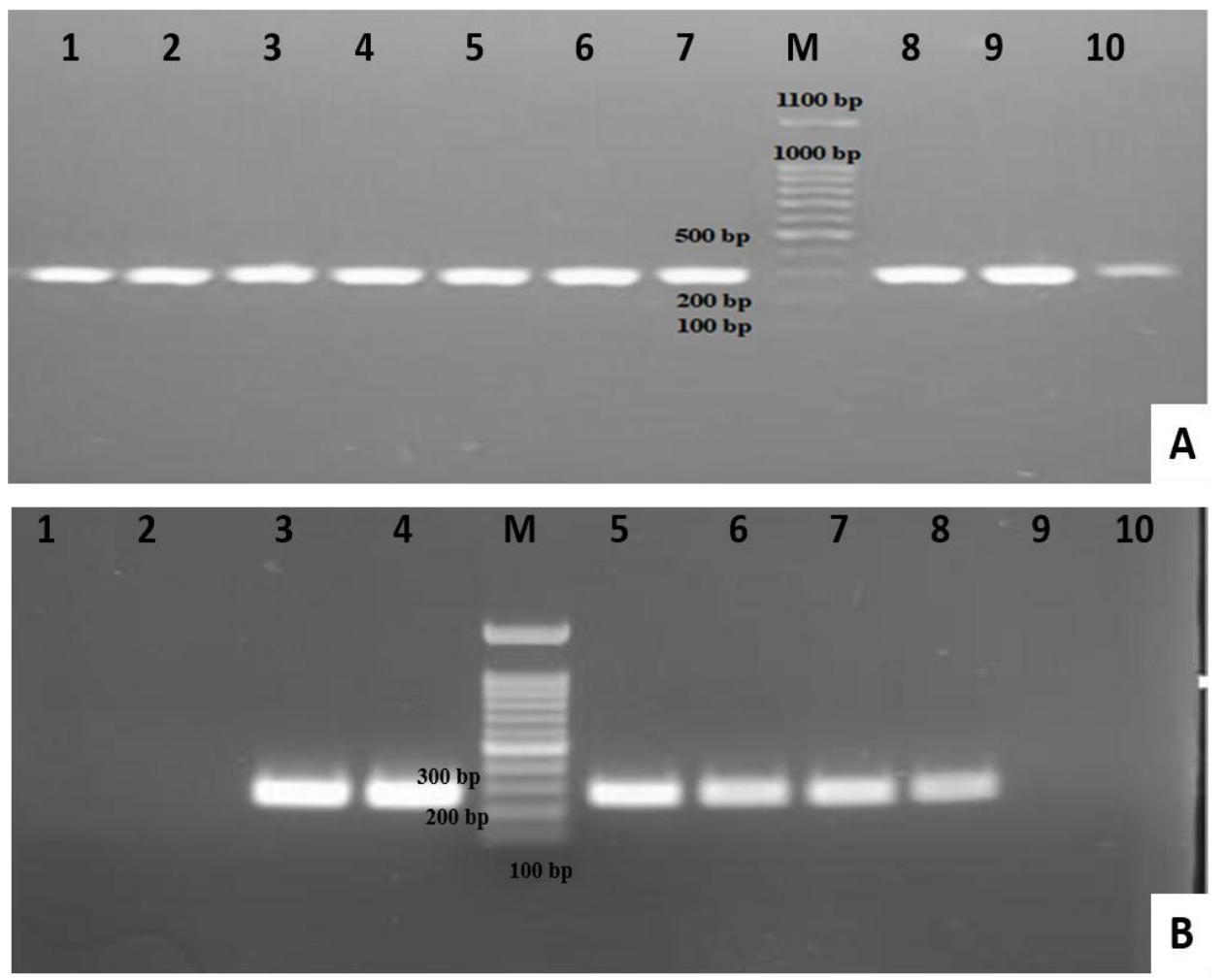

Fig 3-A: Specific PCR of Arcobacter spp. isolates for detecting pldA virulence gene using pldA-f and pldA-r primers that yielded (293 bp). 3-B: Specific PCR of Arcobacter spp. isolates for detecting tlyA virulence gene using tlyA-f and tlyA-r primers that yielded (230 bp).

\section{Antimicrobial susceptibility}

Fish Arcobacter spp. isolates were sensitive to amikacin, cefepime, sulphatrimethoprim and ciprofloxacin as shown in Table (4). Regarding the chicken Arcobacter 
spp. isolates, this study showed that all chicken Arcobacter were highly sensitive to ciprofloxacin followed by aztreonam, imipenem and amikacin.

Table 4: Antibiotic resistant phenotypic of Arcobacter spp. isolates recovered from chicken and fish; $\mathrm{S}$ : senestive, I: intermediate, R: resistant

\begin{tabular}{|c|c|c|c|c|c|c|c|c|c|c|c|c|}
\hline \multirow[t]{3}{*}{ Antibiotics } & \multicolumn{6}{|c|}{$\begin{array}{c}\text { The Nile tilapia isolates } \\
\text { (8 isolates) }\end{array}$} & \multicolumn{6}{|c|}{$\begin{array}{l}\text { poultry isolates } \\
(8 \text { isolates })\end{array}$} \\
\hline & \multicolumn{2}{|c|}{$\mathbf{S}$} & \multicolumn{2}{|c|}{$\mathbf{I}$} & \multicolumn{2}{|c|}{$\mathbf{R}$} & \multicolumn{2}{|c|}{$\mathbf{S}$} & \multicolumn{2}{|c|}{$\mathbf{I}$} & \multicolumn{2}{|c|}{$\mathbf{R}$} \\
\hline & NO. & $\%$ & NO. & $\%$ & NO. & $\%$ & NO. & $\%$ & NO. & $\%$ & NO. & $\%$ \\
\hline Ceftazidime $(30 \mu \mathrm{g})$ & 2 & 25 & 2 & 25 & 4 & 50 & 0 & 0 & 4 & 50 & 4 & 50 \\
\hline $\begin{array}{l}\text { Ampicillin-sulbactam } \\
(20 \mu \mathrm{g})\end{array}$ & 0 & 0 & 0 & 0 & 8 & 100 & 0 & 0 & 0 & 0 & 8 & 100 \\
\hline Aztreonam $(10 \mu \mathrm{g})$ & 6 & 75 & 0 & 0 & 2 & 25 & 8 & 100 & 0 & 0 & 0 & 0 \\
\hline Cefepime $(30 \mu \mathrm{g})$ & 6 & 75 & 2 & 25 & 0 & 0 & 6 & 75 & 2 & 25 & 0 & 0 \\
\hline Amikacin & 8 & 100 & 0 & 0 & 0 & 0 & 8 & 100 & 0 & 0 & 0 & 0 \\
\hline Imipeneme $(10 \mu \mathrm{g})$ & 4 & 50 & 2 & 25 & 2 & 25 & 8 & 100 & 0 & 0 & 0 & 0 \\
\hline Cephalexin $(30 \mu \mathrm{g})$ & 5 & 63 & 2 & 25 & 1 & 13 & 2 & 25 & 4 & 50 & 2 & 25 \\
\hline Gentamicin & 4 & 50 & 4 & 50 & 0 & 0 & 6 & 75 & 2 & 25 & 0 & 0 \\
\hline Ceftriaxone $(30 \mu \mathrm{g})$ & 7 & 88 & 1 & 12 & 0 & 0 & 6 & 75 & 2 & 25 & 0 & 0 \\
\hline Ciprofloxacin $(5 \mu \mathrm{g})$ & 8 & 100 & 0 & 0 & 0 & 0 & 8 & 100 & 0 & 0 & 0 & 0 \\
\hline $\begin{array}{l}\text { Sulphatrimethoprime } \\
(25 \mu \mathrm{g})\end{array}$ & 7 & 88 & 0 & 0 & 1 & 12 & 5 & 63 & 0 & 0 & 3 & 37 \\
\hline Doxycycline $(30 \mu \mathrm{g})$ & 4 & 50 & 3 & 38 & 1 & 13 & 1 & 12 & 7 & 88 & 0 & 0 \\
\hline Ampicillin $(10 \mu \mathrm{g})$ & 0 & 0 & 0 & 0 & 8 & 100 & 0 & 0 & 0 & 0 & 8 & 100 \\
\hline Cefotaxime $(30 \mu \mathrm{g})$ & 0 & 0 & 0 & 0 & 8 & 100 & 0 & 0 & 0 & 0 & 8 & 100 \\
\hline
\end{tabular}

\section{DISCUSSION}

According to several literature, cultural characters and biochemical tests are often unable to precisely identify Arcobacter species because of the heterogeneity that exists within the genus (Laishram et al., 2016). Additionally, biochemical and morphological similarities between Arcobacter and Campylobacter could result in misrecognition of arcobacters as Campylobacter. In this study, combining phenotypic characters with PCR assay specific for genus Arcobacter was successful to differentiate between Arcobacter 
and Campylobacter. In addition, species-specific PCR assay was successful in identifying A. skirrowii, A. butzleri and A. cryaerophilus. The present results are coincided with those of Atabay et al. (2006) and Laishram et al. (2016). Fish, shellfish and chicken are considered as natural carriers for several Arcobacter spp. and they act as possible sources of human infection with Arcobacter (Collado \& Figueras, 2011), particularly when those products were engulfed raw or lightly cooked (Levican et al., 2012). In this study, Arcobacter isolates were successfully recovered in high percentages of $28 \%, 18 \%$ and $18 \%$ from the chicken cloaca, chicken pieces and fish intestine, respectively. These results are similar to the previous studies that isolated Arcobacters from faeces and the intestines of moribund animals (Atabay et al., 2006; Laishram et al., 2016). Meat products of animal origin contaminated with faecal material in slaughters are considered the main sources of the transmission of Arcobacter spp. to human. In this study, Arcobacter spp. were interestingly isolated from water ponds fertilized using raw poultry manure. Therefore, the contamination of aquatic environment with poultry and large animal manures has raised alarms regarding piscine and aquatic environment being vehicles for Arcobacter transmission, highlighting the necessity for more risk assessment studies (Laishram et al., 2016). Contaminated ground water, surface water, drinking water, sea water and raw sewage with faecal material are another significant source of Arcobacter spp. dissemination (Laishram et al., 2016).

Sequencing of $16 \mathrm{~S}$ rRNA gene is considered the golden tool for phylogenetic relatedness among different bacterial species and the reconstruction of evolutionary history. In this study, $16 S$ rRNA gene sequence analysis proved to be a particularly wellsuited tool for phylogenetic studies of the genus Arcobacter. Moreover, analysis of nucleotide sequence and phylogenetic tree construction from different house-keeping genes could upgrade our understanding of Arcobacter epidemiology and bacterial population structure. Interestingly, one Arcobacter fish isolate did not fully identify to species level using the species-specific PCR assay. The phenotypic identification of this fish strain demonstrated homogeneity with Arcobacter genus, while the genetic identification by sequencing $16 \mathrm{~S}$ rRNA confirmed its belonging to A. cloacae with bootstrap value of $100 \%$. Sequencing $16 \mathrm{~S}$ rRNA gene combined with phylogenetic analysis could differentiate $A$. cloacae from A. skirrowii, A. butzleri and A. cryaerophilus. The phylogenetic analysis of A. cloacae, A. skirrowii, A. butzleri and A. cryaerophilus isolated from fish and fowl were clearly embedded within the genus of Arcobacter and grouped with some Arcobacter spp. of human origin pointing out the zoonotic importance of those isolates.

Fish and fowl isolates of Arcobacter spp. harbored two virulence ( $p l d A$ and tlyA) genes and showed various sensitivity to different antibiotic disc. There are several documents suggesting that Arcobacter isolates could carry several virulence traits that could be responsible in the initiation of disease conditions in human, avian, animal and fishes. pldA gene encoded the outer membrane phospholipase A which hydrolyzes acyl 
ester bonds, while tlyA gene is hemolysin gene (Douidah et al., 2012). In this study, (pldA) gene was detected in 12 fish Arcobacter isolates and in 20 fowl Arcobacter isolates. On the other hand, (tlyA) was detected in 10 fish Arcobacter strains: and in 17 fowl Arcobacter strains. Interestingly, several studies proved that ( $p l d A$ and tlyA) genes were responsible for both hemolytic and cytolytic properties in erythrocytes (Ruiz, 2008; Flanagan et al., 2009). According to the available literature, this is the first description of those genes in fish Arcobacters of the tilapia origin. The clinical importance of those results in fish and avian is still unknown. The present findings could propose that Arcobacter could be emerged as a putative pathogen in piscine and avian.

In this study, antibiogram profiling of Arcobacters recovered from chicken and fish samples were investigated. Fowl Arcobacters showed the highest susceptibility to ciprofloxacin followed by aztreonam, imipeneme and amikacin, while fish Arcobacters showed sensitivity to amikacin, cefepime, sulpha-trimethoprim and ciprofloxacin. It was previously shown that they were completely resistant to vancomycin, trimethoprim, rifampicin, cephalothin and ceftriaxone, and were highly susceptible to oxytetracycline, ciprofloxacin, tetracycline, erythromycin, amikacin, kanamycin, gentamicin and enrofloxacin (Ramees et al., 2017). The increased resistance of Arcobacters towards antibiotics could be predisposed by several factors, including the improper usage of antibiotics in animal farms, and source of water. The resistance levels towards the other antibiotics used are documented in Table (4).

\section{CONCLUSION}

To sum up, the current results revealed noticeable homogeneity in the term of virulence genes distribution, antibiotic susceptibility and $16 \mathrm{~S} r R N A$ sequence analysis between Arcobacter spp. isolates from fowl and the tilapia. The phenotypic, molecular and phylogenetic analysis confirmed that A. butzleri and A. skirrowii are the major Arcobacter species in fowl and the tilapia. In addition, fowl and fish Arcobacter spp. harbored some virulence genes that may be responsible of the pathogenicity of Arcobacter spp. Those data pose public health significance especially to farmers and livestock handlers. Therefore, fowl and fish Arcobacter species should not be underestimated as putative pathogens in aquatic $\&$ avian species.

\section{REFERENCES}

Abdelsalam, M.; Eissa, A.E., and Chen, S.C. (2015a). Genetic diversity of geographically distinct Streptococcus dysgalactiae isolates from fish. Journal of advanced research., 6(2): 233-238. 
Abdelsalam, M.; Elgendy, M.Y.; Shaalan, M.; Moustafa, M., and Fujino, M. (2017). Rapid identification of pathogenic streptococci isolated from moribund red tilapia (Oreochromis spp.). Acta Veterinaria Hungarica, 65(1): 50-59.

Abdelsalam, M.; Fujino, M.; Eissa, A.E.; Chen, S.C. and Warda, M. (2015b). Expression, genetic localization and phylogenic analysis of NAPlr in piscine Streptococcus dysgalactiae subspecies dysgalactiae isolates and their patterns of adherence. Journal of advanced research., 6(5):747-55.

Abu-Elala, N.; Abdelsalam, M.; Marouf, S. and Setta, A. (2015). Comparative analysis of virulence genes, antibiotic resistance and gyrB-based phylogeny of motile Aeromonas species isolates from Nile tilapia and domestic fowl. Letters Applied Microbiology, 61 (5):429-436

Atabay, H.I.; Wainø, M. and Madsen, M. (2006). Detection and diversity of various Arcobacter species in Danish poultry. International Journal of Food Microbiology., 109: 139-145

Aydin, S.;Gliltepe, N. and Yildiz, H. (2000). Natural and experimental infections with Campylobacter cryoarophilus in rainbow trout: Gross pathology, bacteriology, cHnical pathol- ogy, and chemotherapy. Fish Pathology., 35: 117-123.

Aydin, S.; Engin, M. and Bircan, R. (2002). A comparative investigation of Arcobacter cryaerophilus infection among Albino crosses and high- and low-body-weight rainbow trout. Journal of Aquatic Animal Health., 14: 39-44.

Augustine, I. and Shukla, R. (2015) An analysis of opportunities and challenges in chicken sector in global and indian prespevtives. International Journal of Management and Social Science., $3: 27-35$.

Bath, G.F.; Leask, R.; Pettey, K.P. and Coetzee, D.J. (2013). Abortions in sheep associated with Arcobacter skirrowii infection. The Journal of the South African Veterinary Association., 84:4. https://doi.org/ 10.4102/jsava.v84i1.952

Collado, L. and Figueras, M.J. (2011). Taxonomy, epidemiology and clinical relevance of the genus Arcobacter. Clinical Microbiology Reviews., 24:174-192.

Douidah, L.; de Zutter, L.; Bare, J.; De Vos, P.; Vandamme, P.; Vandenberg, O., Van den Abeele, A.M. and Houf, K. (2012). Occurrence of putative virulence genes in Arcobacter species isolated from humans and animals. Journal of Clinical Microbiology., 50:735-741.

Eissa, A. E. (2016). Clinical and Laboratory Manual of Fish Diseases. LAP LAMBERT Academic Publishing.

Eissa, A.E.; Abdelsalam, M.; Abumhara, A.; Kammon, A.; Gammoudi, F.T.; Ben Naser, K.M. and Asheg, A. (2015). First record of Vibrio vulnificus/Anisakis pegreffi concurrent infection in black scorpionfish (Scorpaena porcus) from the South Mediterranean basin. Research Journal of Pharmaceutical Biological and Chemical Sciences., 6(3): 1537-1548. 
Eissa, A.E.; Hussein, H.A. and Zaki, M.M. (2012). Detection of avian influenza (H5N1) In some fish and shellfish from different aquatic habitats across some Egyptian provinces. Life Science Journal., 9(3): 2702-2712.

Fisher, J.C.; Levican, A.; Figueras, M.J. and McLellan, S.L. (2014). Population dynamics and ecology of Arcobacter in sewage. Frontiers in Microbiology., 5:1-9.

Flanagan, R.C.; Neal-McKinney, J.M.; Dhillon, A.S.; Miller, W.G. and Konkel, M.E. (2009). Examination of Campylobacter jejuni putative adhesins leads to the identification of a new protein, designated FlpA, required for chicken colonization. Infection and Immunity., 77:2399-2407.

Hall, T.A. (1999). Bioedit: A user friendly biological sequence alignment editor and analysis program for Windows 95/98/NT. Nucleic Acids Symposium Series., 41: 95-98.

Harmon, K.M. and Wesley, I.V. (1996). Identification of Arcobacter isolates by PCR. Letters in Applied Microbiology., 23:241-244.

Hassan, A.K., (2017). Detection and Identification of Arcobacter species in Poultry in Assiut. Journal of Advanced Veterinary Research., 7: 53-58

Hassan, H.; Mohamed, E.; Abdel Fatah, H. and Karima, A. (2019). An analytical Economic Study of Fish Production in Egypt. Middle East Journal of Agriculture Research., 8: 139-152

Ho, H.T.; Lipman, L.J.A.; Van der Graaf-van Bloois, L.; Van Bergen, M. and Gaastra, W. (2006). Potential routes of acquisition of Arcobacter species by piglets. Veterinary Microbiology., 114:122-133.

Houf, K., De Zutter, L., Van Hoof, J. and Vandamme, P. (2002). Assessment of the genetic diversity among arcobacters isolated from poultry products by using two PCRbased typing methods. Applied Environmental Microbiology., 68:2172-2178.

Jakeen, E.J.; Elshamy, S.; Hassan, A.W.; Abdelsalam, M.; Younis, N.; El-Hady, M.A. and Eissa, A.E. (2020). Isolation and characterization of mycoplasmas from some moribund Egyptian fishes. Aquaculture International., 28(3): 901-912.

Kumar, S.; Stecher, G. and Tamura, K. (2016). MEGA7: Molecular Evolutionary Genetics Analysis Version 7.0 for Bigger Datasets. Molecular Biology and Evolution., 33:1870-1874. doi:10.1093/molbev/msw054

Laishram, M.; Rathlavath, S.; Lekshmi, M.; Kumar, S. and Nayak, B. (2016). International Journal of Food Microbiology Isolation and characterization of Arcobacter spp . from fresh seafood and the aquatic environment. International Journal of Food Microbiology., 232: 87-89

Levican, A.; Collado, L.; Aguilar, C.; Yustes, C.; Dieguez, A.L.; Romalde, J.L. and Figueras, M.J. (2012). Arcobacter bivalviorum sp. nov. and Arcobacter venerupis sp. nov., new species isolated from shellfish. Systemic Applied Microbiology.,35(3):133138. 
Maugeri, TL, Irrera, G.P.; Lentini, V.; Carbone, M.; Fera, M.T and; Gugliandolo, C. (2005). Detection and enumeration of Arcobacter spp. in the coastal environment of the straits of Messina (Italy). New Microbiology., 28:177-182.

Omojowo, F. and Omojasola, F. (2013). Antibiotic Resistance Pattern Of Bacterial Pathogens Isolated From Chicken Manure Used To Fertilize Fish Ponds In New Bussa, Nigeria. Albanian Journal of Agricultural Sciences., 12: 81-85.

Prithwiraj, J., Barat S. and Chitta N.R. (2008). Fish production, water quality and bacteriological parameters of Koi carp ponds under live-food and manure based management regimes. Zoological Research., 29 (2): 165 - 173.

Rahimi, E. (2014). Prevalence and antimicrobial resistance of Arcobacter species isolated from poultry meat in Iran. British Poultry Science., 55:174-180.

Ramees, T.P.; Dhama, K.; Karthik, K.; Rathore, R.S.; Kumar, A.; Saminathan, M.; Tiwari, R.; Malik, Y.S. and Singh, R.K. (2017). Arcobacter : an emerging food-borne zoonotic pathogen, its public health concerns and advances in diagnosis and control - a comprehensive review, Veterinary Quarterly., 37(1): 136-161, DOI: 10.1080/01652176.2017.1323355.

Ruiz, N. (2008). Bioinformatics identification of MurJ (MviN) as the peptidoglycan lipid II flippase in Escherichia coli. Proceedings of the National Academy of Sciences of the United States of America., 105:15553-15557.

Scarano, C.; Giacometti, F.; Manfreda, G.; Lucchi, A.; Pes, E.; Spanu, C.; De Santis, E.P. and Serraino, A. (2014). Arcobacter butzleri in sheep ricotta cheese at retail and related sources of contamination in an industrial dairy plant. Applied Environmental Microbiology., 80:7036-7041.

Shah, A.H.; Saleha, A.A.; Zunita, Z. and Murugaiyah, M. (2011). Arcobacter-an emerging threat to animals and animal origin food products?. Trends in Food Science and Technology., 22:225-236.

Suelam, A. (2013). Isolation and identification of Arcobacter species recovered from rabbits in Zagazig, Egypt. Suez Canal Veterinary Medical Journal., 18(1):129-138.

Van den Abeele, A.M.; Vogelaers, D.; Van Hende, J. and Houf, K. (2014). Prevalence of Arcobacter species among humans, Bel- gium, 2008-2013. Emerging Infectious Diseases., 20:1731-1734.

Wesley, I.V. and Baetz, A.L. (1999). Natural and experimental infections of Arcobacter in poultry. Poultry Science., 78:536-545.

Weinstein, M.P. and Lewis, J.S. (2020). The clinical and laboratory standards institute subcommittee on antimicrobial susceptibility testing: background, organization, functions, and processes. Journal of clinical microbiology., 58(3):1-7

Yildiz, H. and Aydin, S. (2006). Pathological effects of Arcobacter cryaerophilus infection in rainbow trout (Oncorhynchus mykiss Walbaum). Acta Veterinaria Hungarica., 54: 191-199 